\title{
Microseismicity Study of the El Hoyo-Monte Galan Geothermal Prospect, Nicaragua
}

\author{
Albert. T. Smith and Paul Kasameyer \\ Lawrence Livermore National Laboratory
}

July 1997

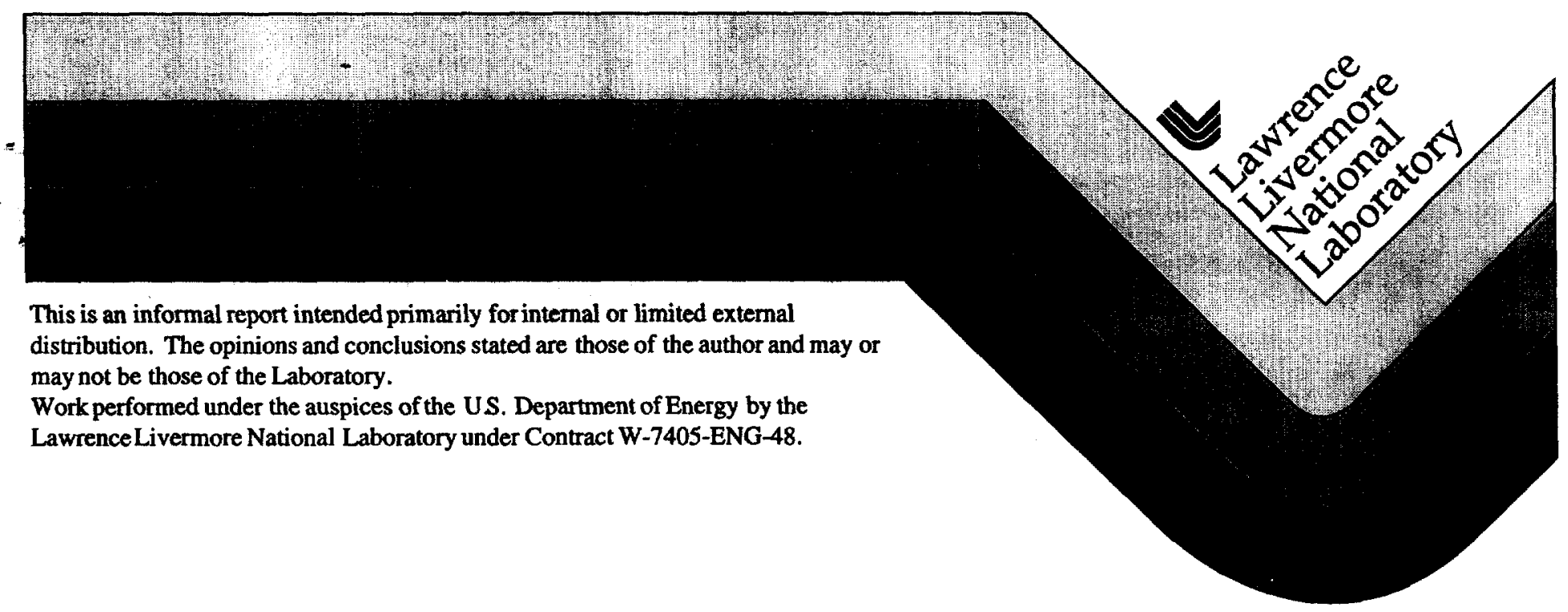




\section{DISCLAIMER}

This document was prepared as an account of work sponsored by an agency of the United States Government. Neither the United States Government nor the University of California nor any of their employees, makes any warranty, express or implied, or assumes any legal liability or responsibility for the accuracy, completeness, or usefulness of any information, apparatus, product, or process disclosed, or represents that its use would not infringe privately owned rights. Reference herein to any specific commercial product, process, or service by trade name, trademark, manufacturer, or otherwise, does not necessarily constitute or imply its endorsement, recommendation, or favoring by the United States Government or the University of California. The views and opinions of authors expressed herein do not necessarily state or reflect those of the United States Government or the University of California, and shall not be used for advertising or product endorsement purposes.

This report has been reproduced directly from the best available copy.

Available to DOE and DOE contractors from the Office of Scientific and Technical Information

P.O. Box 62, Oak Ridge, TN 37831

Prices available from (615) 576-8401, FTS 626-8401

Available to the public from the

National Technical Information Service

U.S. Department of Commerce

5285 Port Royal Rd.,

Springfield, VA 22161 


\title{
Microseismicity Study of the \\ El Hoyo-Monte Galan Geothermal Prospect, \\ Nicaragua
}

\author{
Albert. T. Smith and Paul Kasameyer \\ Lawrence Livermore National Laboratory \\ July 1997
}

\section{Summary}

We installed 12 seismometers in a small array in the El Hoyo-Monte Galan area of Nicaragua for 20 days. We detected a vertically elongate cluster of episodic microseismicity from 6 to $3 \mathrm{~km}$ depth to the northwest of El Hoyo. The seismicity consists of small clusters of events whose structure could not be resolved. A composite focal mechanism model indicates nearly horizontal $\mathrm{N} 30^{\circ} \mathrm{W}$ compression or nearly horizontal $\mathrm{N} 60^{\circ} \mathrm{E}$ tension.

\section{Introduction}

The geography of the Pacific coast of Nicaragua is dominated by features caused by the descending Cocos Plate and the motion of the Caribbean Plate. Weinberg (1992) describes the last three stages in that area's tectonic history: Late Miocene to Farly Pliocene trenchparallel crustal shortening; Plio-Pleistocene extension, forming the Nicaraguan Graben which parallels the coast; and the continuing opening of the Nicaraguan Graben by rightlateral motion on en-echelon lines of volcanoes lying sub-parallel to the coast.

The character of the current deformation is indicated in Figure 1. The combination of large sources of magma caused by melting of the down-going slab and the tectonic history of extension due to the western motion of the Caribbean Plate produce the active volcanoes of Nicaragua and open structural features such as faults within the crust that can act as conduits for geothermal fluids. This report describes one element of a detailed study near the three volcanoes just west of Lake Managua: Momotombo, Monte Galan and El Hoyo.

A series of seismic experiments and possible exploratory drilling in the El Hoyo - Monte Galan region of Nicaragua gives an opportunity to test geophysical methods for defining possible geothermal conduits. One of these, microseismicity, may help discern the locations of active faults. At the same time, the characteristics of seismic propagation might point towards region of high crack density and fluid content. Combining these potential diagnostics with EM, gravity methods, near-surface temperatures, and the locations of hot springs may reveal the conduits for near surface geothermal activity. This report summarizes the results of a microseismicity survey carried out by Lawrence Livermore National Laboratory in March and April 1996 to look for seismic signatures of geothermal conduits.

\section{Justification for deployment of a closely spaced seismic network}

The Nicaraguan geological agency, INETER, with cooperation from the Swiss seismologists from ETH-Z, operates a seismic network to monitor seismicity and geologic hazards in the Marabios range. Figure 2 illustrates the detection capability of this network. It shows the locations of seismic events within our study region as determined by the Nicaraguan network. Seismic stations used to locate these events are primarily outside this figure, thus only events larger than about 2.5 are located. During early April, a large 
number of events occur near Momotombo as signs of volcanic activity occur with the volcano. Only a scattering of events was detected within our study area between Momotombo and El Hoyo. Defining possible fracture zones requires microseismicity observations to magnitude 1.5 or even less.

\section{Design of Seismic Experiment}

We designed the seismic experiment to allow accurate location of microseismicity and to profile the velocity structure using explosions in the adjacent lake and airgun blasts in the Pacific Ocean. Limited access tended to restrict instrument locations to areas accessible by road and made mountainous areas such as El Hoyo difficult as a possible site. We installed stations in a crossed pattern with station spacings of approximately $2 \mathrm{~km}$. The station layout is plotted as small crosses in Figure 2. During part of the deployment, INETER/ETHZ deployed an additional array on an intermediate scale between our detailed survey and the Nicaraguan National net. We have not yet combined the data from these three deployments.

Airgun shots were planned in the Pacific along the trend of the North-South oriented station sites and an explosion was planned in the lake near the bottom of the figure, at the location marked by the date 960328 . Both would be adequately recorded by the stations as a NS profile. The East-West oriented stations would then provide a fan profile. The hope was to detect strong propagation and attenuation changes as the propagation passes under El Hoyo.

We installed 12 three-component REFTEK seismic recording systems with Sprengnether S-6000 seismometers at the locations shown on Figure 2. The detailed locations, as determined by GPS, are listed in Table I. We recorded natural and man-made seismic signals continuously from March 20 to April 9, 1996, at frequencies up to $50 \mathrm{~Hz}$. We recorded a number of oceanic airgun shots, and two moderate sized explcsions that took place in Lake Managua on behalf of INETER. In addition, we recorded several thousand seismic events at distances ranging from $100 \mathrm{~km}$ to less than $2 \mathrm{~km}$ from the center of the network.

Our experimental design allowed us to adequately detect and locate seismic events within the network and near El Hoyo. We made no attempt to extend the network closer to Momotombo, a zone outside our target region. During the latter half of the experiment, we moved the station LW0 to the east of El Hoyo as LSW1 for additional control on seismic events within the study area. Unfortunately, the station primarily recorded events from Momotombo and only a few within the network.

\section{Location Analysis}

Traditional location analysis of seismic data begins with HYPO71, a routine producing an independent location for each event using a specified velocity model with station corrections. Our initial solutions use the velocity model adopted by the Nicaraguans for their regional solutions. No station corrections are used for HYPO71 solutions.

Figure 3 plots the preliminary locations based on solutions from HYPO71 (Lee and Lahr, 1975) along with station locations represented by crosses. Only events with errors of $5 \mathrm{~km}$ 
or less are plotted and the error circles are outlined in red. Events significantly outside the network of stations may have large systematic errors that are not reflected in the error circles. Near El Hoyo a cluster of well located, shallow events occur and a trend of events continues to the southwest from the cluster. Many events occurred during the beginning of April near Momotombo to the lower right in the diagram.

The relative locations of clustered events near El Hoyo are of special interest. Near the volcano the velocity structure could be very heterogeneous, reflecting the deposition of ash and lava flows, intrusion of dikes, or reworking through the flow of geothermal fluids. These heterogeneities can pull the locations and create a systematic error that is very difficult to pin down unless a known source exists at depth, or independent information is available. The relative positions of events within a cluster, however, can be resolved since the ray paths to each station are relatively constant. By performing a joint solution for all the event locations and a common time error at each seismic station, we can eliminate much of the uncertainty, because the station correction compensates in an average sense for common heterogeneity along the path. This is the approach taken by the location code VELEST.

VELEST, or velocity estimation, is designed to derive both the best one-dimensional velocity model and average station correction in addition to a simultaneous location of all events. Originally written in 1976 by Ellsworth and Roecker as HYPO2D for seismic tomography, it had been extensively modified in the intervening years. After extensive programming by Kradolfer and Mauer (Kissling, 1988), the code provides a reliable method to calculate a 'Minimum 1-D model'(a well-suited 1-D velocity model for earthquake location and for 3-D seismic tomography). Its capabilities are best documented in Kissling et al. (1994) and Kissling et al.(1995). For the inversions described here, we used VELEST version 3.2 .

VELEST solves jointly for the locations of all events and iterates to an "improved" $P$ and $S$ velocity model plus the $P$ and $S$ station corrections. Determining the velocity model is actually a non-linear process and is dependent upon the initial velocity model. Low-velocity zones are particularly difficult and are highly non-linear. In addition, $\mathrm{P}$ and $\mathrm{S}$ velocities are solved independently, allowing the ratio of the velocities to significantly vary. Both these may introduce instabilities in the velocity model unless iterations are sufficiently damped and many event-station combinations constrain the solution. Unfortunately, our solutions work with a minimum of event-station combinations and potential heterogeneities in the velocities may introduce unstable tradeoffs between velocity structure and station corrections during the iterations. We have tried to resolve these by trying a number of different starting models and by damping the iterations for velocity and station corrections.

Our initial model and hypocentral locations utilize the standard output of HYPO71, a standard location code that uses a fixed velocity model. We start with the velocity model normally used by the Nicaraguan network. To prevent the near surface velocity structure under each station from dominating the velocity iterations during solutions using VELEST, we damped the changes to the $P$ and $S$ wave velocity models more strongly than the station corrections. This allows the "best" solution to start from an initial set of station corrections, which hopefully accommodates the near surface heterogeneity. Figure $4 \mathrm{a}$ plots the locations to obtain the best solution for events over the whole region. These solutions are coded with color representing depth as indicated on the header. The plot 
suggests that the cluster of events lies within a northwest - southeast trend of microseismicity going from the northwest side of El Hoyo to the southwest of Momotombo. Locations of the events to the southwest, near Momotombo, are outside the network. In those situations, events have a large uncertainty, especially in depth, and are probably placed too deep.

Within the study area, the cluster of events near longitude $86^{\circ} 39^{\prime} \mathrm{W}$ and $12^{\circ} 30^{\prime} \mathrm{N}$ represents a series of small events occurring during the whole deployment as a series of "bursts". A joint inversion of velocity and location was executed on only the events within the cluster using VELEST. The resulting velocity model is plotted in Figure $4 \mathrm{~b}$. During the inversion, the velocity was constrained to increase with depth only. The effect of this will be examined in a later section. Figure 5 is an expanded map view of these events based on a detailed inversion using only the cluster. To give an illusion of depth, the size of each event is scaled by its depth where smaller is deeper. The inversion using only the cluster provides a better constraint on the relative locations of the seismic events. Paths to each station are virtually identical, thereby minimizing the impact of heterogeneity on the relative hypocentral locations. The mean location of the whole cluster could still be biased by roughly $0.5 \mathrm{~km}$ by lateral velocity heterogeneity. This estimate of bias is derived from variations using different starting velocity models and damping parameters during the inversion.

Depth sections can further show the relationship between events. Figure 6 and 7 represent depth sections where the color scale now represents the time sequence for their occurrence. Figure 6, the West to East section, suggests two planes of events: the first is shallower and extends from about $3.3 \mathrm{~km}$ to $4 \mathrm{~km}$ in depth; the second deeper plane begins at $4.4 \mathrm{~km}$ and continues to approximately $5 \mathrm{~km}$ depth. The size of each circle reflects the event's distance to the north. Using these cues, we see that the shallow cluster appears as two groups of events. Figure 7, the South-North section, also shows that the first group occurred as two distinct temporal clusters separated by approximately $0.5 \mathrm{~km}$ along a north-south plane. The deeper group is clustered both spatially and in time, but a few events occur early and late in the deployment.

\section{Focal Mechanism}

The stress field associated with this cluster of events can be derived from a compilation of the first motions observed at the seismic stations. The solutions are influenced by the velocity model and location of the events; however, this group of events is sufficiently well controlled to yield good estimates of the stress field. Figure 8 plots lower-hemisphere projections of the focal mechanisms for each event within the cluster. The filled quadrants represent compressional first motion; the open quadrants denote dilational first motion. As a result, the compressional $P$ axis of stress for the solution is centered within the open quadrant, while the tensional $T$ axis falls within the filled quadrants. Within this group of events, the most consistent stress axis appears to be the $P$ compressional axis along a northwest - southeast trend.

A composite solution that sums all the first motions in one focal mechanism is illustrative and might shed some light on the consistency of the solution. Figure 9 is the composite focal solution using almost all the events and based on their specific hypocentral location. The results are actually quite consistent given the range of events. An inspection of the first 
motion and the confidence range of the mechanism supports the N30W trend of the compressional axis and a slightly larger variation in the tensional axis, which lies generally in the N60E direction. Events closer to Momotombo are outside the network and lack sufficient constraints for a reliable focal mechanism.

\section{Other constraints on structure from the microseismicity survey}

A secondary objective of this experiment was to learn about the velocity (and possibly attenuation structure) in El Hoyo - Monte Galan area. Because of the limited spatial extent of our network, and the fact that the earthquakes were clustered, we do not have enough different ray paths to invert for geologic structure based on the seismic L.LNL data alone. However, two man-made sources allow us to draw some conclusions.

Two explosions occurred in Lake Managua during our deployment. We have used signals from the largest to infer a one-dimensional velocity structure, assuming that all beds are flat-lying and that lateral variations can be ignored. More realistic models cannot be resolved by this unreversed refraction profile. Since the precise location and time of the explosion were not known, we used two sources of information to constrain its location. The first is a location and time inferred from seismograms recorded by the Nicaraguan Seismic Network (E. Reuttner, personal communication). Unfortunately, the seismicallydetermined location depends on the velocity model used for locations, which would bias our results. The second approach uses the airwave from the explosion, as recorded on our seismic network. The airwave and first arrivals from the explosion are shown in Figure 10. The time origin was inferred from the zero-intercept of the air-wave curve, and has been removed from all the data, and the distances are plotted relative to a location determined as follows.

Using tabulated values of sound speed, we calculated the explosion distance from each station that recorded an air wave, and used those distances to plot circles on the map as shown in Figure 11. The location of the station was taken to be the point where all the curves are closest together. In practice, they do not converge to a point, because of uncertainty in the path and curvature due to topographic interference and refraction. We found the best convergence occurred for air speeds corresponding to dry air 0 to $20^{\circ} \mathrm{C}$, slower than the speed at the observed temperature of nearly $30^{\circ} \mathrm{C}$. The resulting location is very near the location estimated from the regional seismic array, but the origin time was approximately one second earlier. We think that the actual seismic arrivals are delayed by the thick, near-surface low-velocity layers discussed below, so the air waves were used to define the origin time.

The recorded signals from the explosion are shown in a record section in Figure 11. The signals are all plotted to the same scale, and the decrease in amplitude due to geometrical spreading has been approximately removed by multiplying by the distance from explosion to station. Several features are seen in this figure.

1. The first arrivals move rapidly across the network, with a break in slope to apparent velocity greater than $6 \mathrm{~km} / \mathrm{s}$ at $12 \mathrm{~km}$ distance.

2. The amplitude of the first arrival decreases rapidly at the stations father than $17 \mathrm{~km}$, and an arrival 1 second later dominates the signal. 
3. The amplitudes of both arrivals are small on stations W3, S5 and S6, and late and small on station W4 and W1.

The first two attributes can be duplicated with a one-dimensional velocity model, using the 1-D refraction forward code, R1D, written by J. H. Leutgart (1992). Figure 13 shows one (of many) simple models that fit the arrival times of the first arrivals. This model is characterized by very abrupt velocity changes from 2 to $5 \mathrm{~km}$ depth. The near-surface low velocity layer is about two $\mathrm{km}$ thick; any layer with less slowness will produce earlier arrivals at $7 \mathrm{~km}$ than are seen in the data. The middle layer has a fairly normal velocity, but the velocity jumps to over $6 \mathrm{~km} / \mathrm{s}$ at $4 \mathrm{~km}$ depth. The observed high apparent velocity requires either a sloping interface or a very high velocity layer in the upper crust.

This fast layer does not fit the rapid decrease in amplitude beyond $17 \mathrm{~km}$, nor does it produce the observed second arrival. These features can be duplicated with more complicated models such as that shown in Figure 14. An additional step and a lower velocity zone below $4.5 \mathrm{~km}$ cause a triplication that generates large amplitudes near $10 \mathrm{~km}$ and a strong second arrival. The gradient in the high velocity layer truncates the first arrival around $17 \mathrm{~km}$. Other 1-D models that fit the data require the velocity reversal to truncate the arrival. Of course, the truncation could also be caused by lateral variations in structure or attenuation that are not included in these 1-D models.

If this model with a low-velocity zone is used to relocate events, events near Momotombo are pushed to a greater distance and the cluster of events near El Hoyo tends to spread apart but retain their temporal groupings. The fact that the event locations are more tightly clustered for the velocity model determined from earthquake arrival times suggests (but does not prove) that the refraction-derived model is not appropriate in the vicinity of the cluster. The existence of the low-velocity zone makes the inversion very non-linear; in this situation, we have insufficient data to properly constrain the inversion.

The second man-made source is a series of marine airgun shots off the Pacific Coast of Nicaragua shot by the R/V Sonne for GEOMAR - Research Center for Marine Geosciences, University of Kiel. At the time of this writing, we knew neither the times nor locations of these shots. Figures 15 and 16 show a stacked set of data from the airgun shots, plotted against reduced travel time with an arbitrary origin. Although these sources are much more distant than the explosion, the signals move across the network at about the same speed as the first arrival seen on the explosion records. This observation supports the idea that velocities do not continue to increase below the high velocity layer at $4.5 \mathrm{~km}$ depth. The arrival times from the airgun data recorded over this small network add little additional information about the velocity structure. Like the data from the explosions, these signals vary strongly in amplitude from station to station; however, the pattern of weaker arrivals is different. For example, 55 is very large for the airgun waves that come from the southwest, whereas it is weak for the explosion to the south.

\section{Discussion}

This study has focused on microseismicity within our study area as a method to define possible structural trends. During this period, the seismicity was primarily clustered in a 4 $\mathrm{km}^{3}$ volume just northeast of El Hoyo. Examination of longer-term seismicity data from 
the Nicaraguan net suggests that this cluster has persisted for decades (W. Teplow, personal communication). It is tempting to conclude that this area is related either volcanic activity (as is the large cluster under Momotumbo) or to intense hydrothermal flow. The overall pattern of seismicity suggests a northwest-southeast trend extending from El Hoyo to Momotombo, with a strike that is distinctly more northerly than that of the volcanic trend. This must be carefully interpreted considering the limited spatial extent of our network and it's limited duration.

Recent tectonic and volcanic activity is observed along features rotated clockwise from the volcanic trend throughout Central America. McBirney and Williams (1965) argue for a N$\mathrm{S}$ trend to these secondary features. At El Hoyo these features include the clear graben structure north of the volcanic center, an alignment of vents to the south extending about 5 $\mathrm{km}$ from the axis of the Marabios Range Volcanoes, and a kilometer-long N-S fissure that formed during the 1952 eruption of Los Pilas, one of several interlocking volcanic centers on El Hoyo (McBirney, 1955). McBirney and Williams identified similar trends in the Nejapa Pits near Managua, and at El Viejo, to the north. Weinberg (1992) describes additional features with a larger range of trends, including the N30E sinistral motion on the Tiscapa Fault during the 1972 Managua Earthquake and the N-S alignment of the bounding faults for the Managua depression. He also discusses others work that shows that the north-south alignment of vents is seen in El Salvador and Guatemala as well. Burkart and Self (1985) see similarly NS trending sinistral faults and depressions in northern Central America. These features all indicate a stress regime of NS shortening and EW extension consistent with, but slightly rotated from, our composite focal mechanism. If the fault planes coincide with the nodal plane that parallels the volcanic trend, then the motion of these events is dextral, consistent with the fault motions in Weinberg's figure, and it is possible that the seismicity trend indicates a small "pull-apart" zone similar to the larger ones he discusses.

The velocity structure in Figure 14 is consistent with Elming and Rasmussen's (1997) geophysical interpretation in the Nicaraguan Graben. They inverted magnetotelluric and gravity data in the Nicaraguan Graben about $40 \mathrm{~km}$ southwest of our site, and found that the conductive, low-density alluvial and volcanic rocks filling the graben are up to $2 \mathrm{~km}$ thick, consistent with our thick, near-surface zone. This zone is underlain by a resistive $(1000 \mathrm{ohm}-\mathrm{m})$ layer that corresponds in depth to our rapidly increasing velocities to above $6 \mathrm{~km} / \mathrm{s}$. They also see a lower crustal conductor (deeper than $13 \mathrm{~km}$ ) that they attribute to partial melt: If this feature corresponds to the lower velocities we see at depth, it must be considerably shallower.

The amplitude variations in the seismic signals are intriguing. If interpreted literally, they suggest stronger attenuation and delays for paths in three areas: under El Hoyo, along a northward line from the explosion through Cerro Montoso to station LS7, and in an area just northeast of the seismic cluster discussed above. These results are very speculative, but they could be made more secure by analysis of data from other seismic deployments that took place in the area.

This seismic deployment has provided strong evidence for an earthquake cluster that is associated with localized extension within an active extensional area. Because of the limited spatial extent of seismic sources and receivers, we cannot determine whether other features in the data are caused by structural variations or by attenuation variations. Under certain 
assumptions that have to be evaluated, we see some evidence for constraints on the depth of volcanic and alluvial fill, and for very high crustal velocities at depths shallower than 5 $\mathrm{km}$. Finally, this study has provided tantalizing suggestions that there is a velocity inversion in the upper crust and that zones of high attenuation are associated with some volcanoes. These observations will contribute, along with other geophysical, geological and geochemical observations, to the development of conceptual model for the El Hoyo Monte Galan area.

\section{Acknowledgments}

This work was carried out in cooperation with Trans-Pacific Geothermal under funding from the U.S. Department of Energy Geothermal Program, under the direction of Marshall Reed. Don Rock, J. Patrick Lewis, Eduardo Majorca and Alejandro Acosta were responsible for the instrumentation, installation and data collection, and Nick Sharp provided valuable help shipping as we mobilized. W. Strauch, of INETER, and E. Kissling and E. Reuttner of ETH, provided valuable in-country support and helped us decide on the experimental design. This work was performed under the auspices of the U.S. Department of Energy by the Lawrence Livermore National Laboratory under Contract W-7405-ENG-48 


\section{Tables}

Table I. Locations of Stations

\begin{tabular}{|l|l|l|}
\hline \multicolumn{1}{|c|}{ Station Name } & \multicolumn{1}{|c|}{$\begin{array}{c}\text { Latitude (N), } \\
\text { decimal degrees }\end{array}$} & $\begin{array}{c}\text { Longitude (W), } \\
\text { decimal degrees }\end{array}$ \\
\hline LS1 & 12.43740 & 86.62373 \\
\hline LS2 & 12.45447 & 86.62086 \\
\hline LS3 & 12.47023 & 86.61645 \\
\hline LS4 & 12.48599 & 86.60342 \\
\hline LS5 & 12.51165 & 86.59329 \\
\hline LS6 & 12.53635 & 86.58440 \\
\hline LS7 & 12.55266 & 86.58202 \\
\hline LW0 & 12.55306 & 86.70510 \\
\hline LW1 & 12.54233 & 86.67111 \\
\hline LW2 & 12.53413 & 86.65813 \\
\hline LW3 & 12.51798 & 86.63064 \\
\hline LW4 & 12.51374 & 86.61118 \\
\hline LW6 & 12.51722 & 86.56620 \\
\hline LSW1 & 12.48334 & 86.63095 \\
\hline
\end{tabular}




\section{Figures}

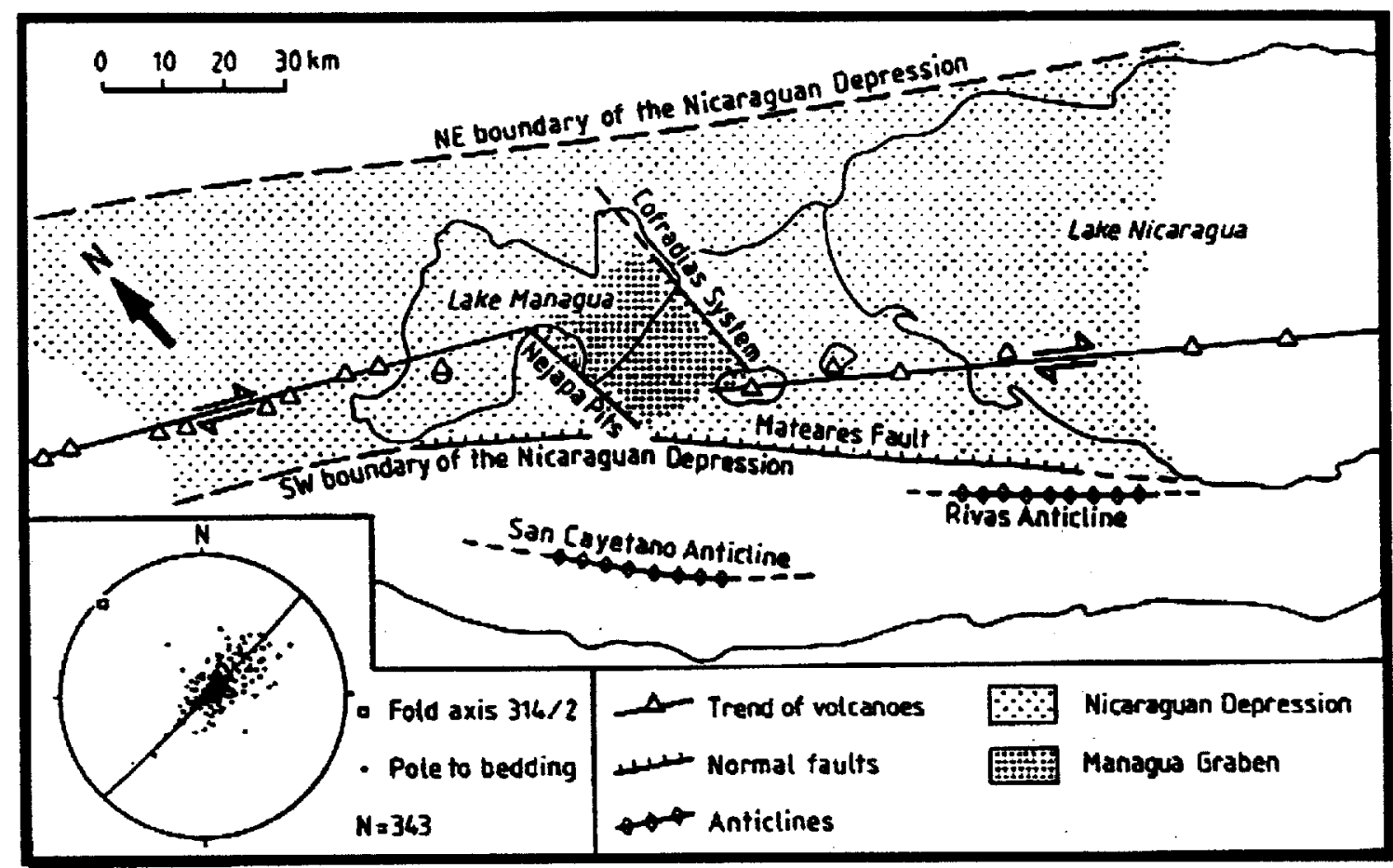

Figure 1. Map of Western Nicaragua, showing major structural features (from Weinberg, 1992). The current deformation occurs as right-lateral slip along the NW-SE line of volcanoes, and in pull-apart basins caused by left-ward offsets of those features. 


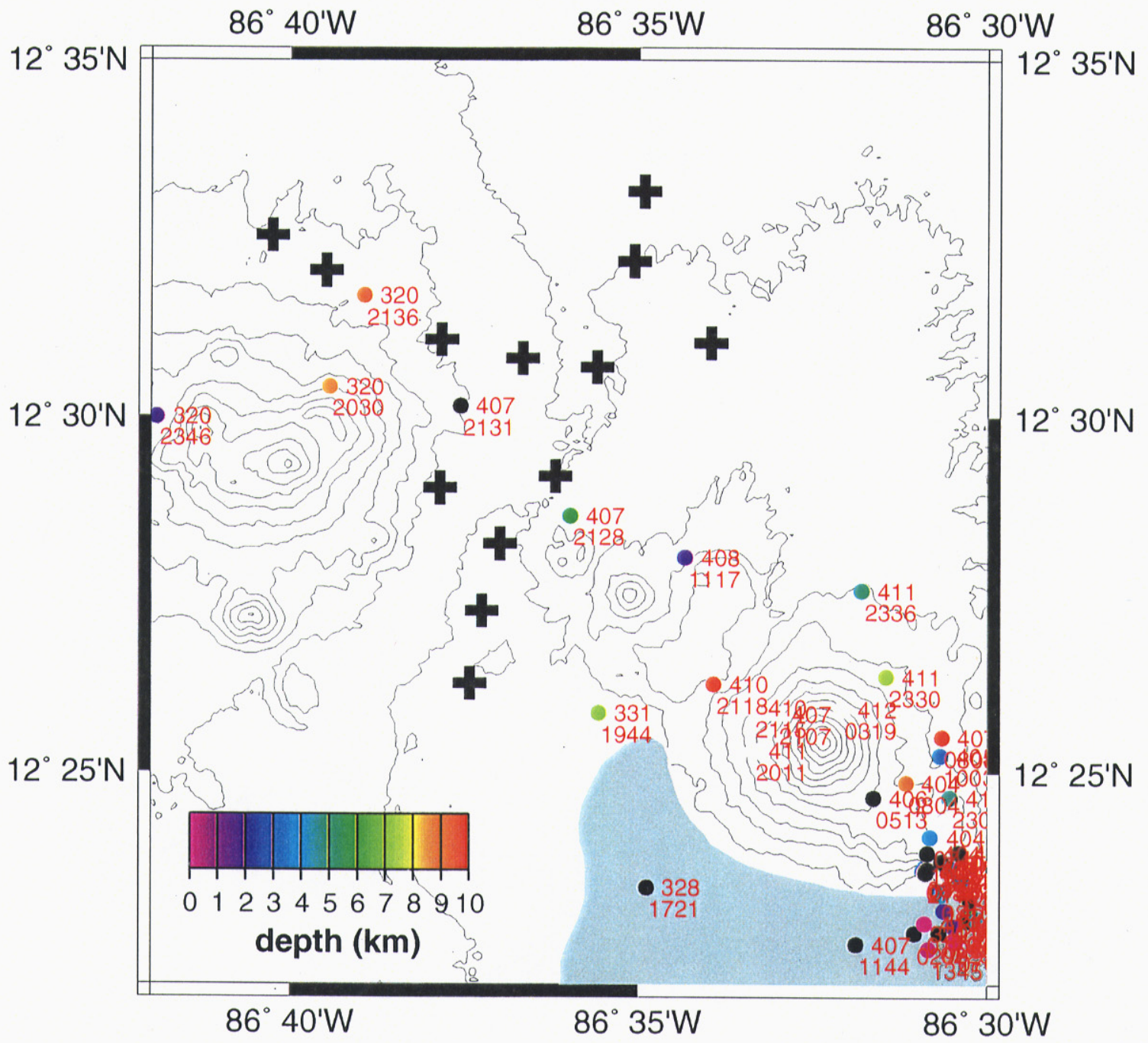

Figure 2. Seismic events located in the study area by the Nicaraguan net (Reuttner, personal communication). The circles represent all events that were located during the period March 20 through April 9 in this area. Depth is coded by color as shown in the legend. The locations of our stations are marked by crosses in this and subsequent figures. The topographic contour interval is $100 \mathrm{~m}$ for this and following figures. This and following maps were made using the Generic Mapping Tools software package (Smith and Wessel, 1995). 


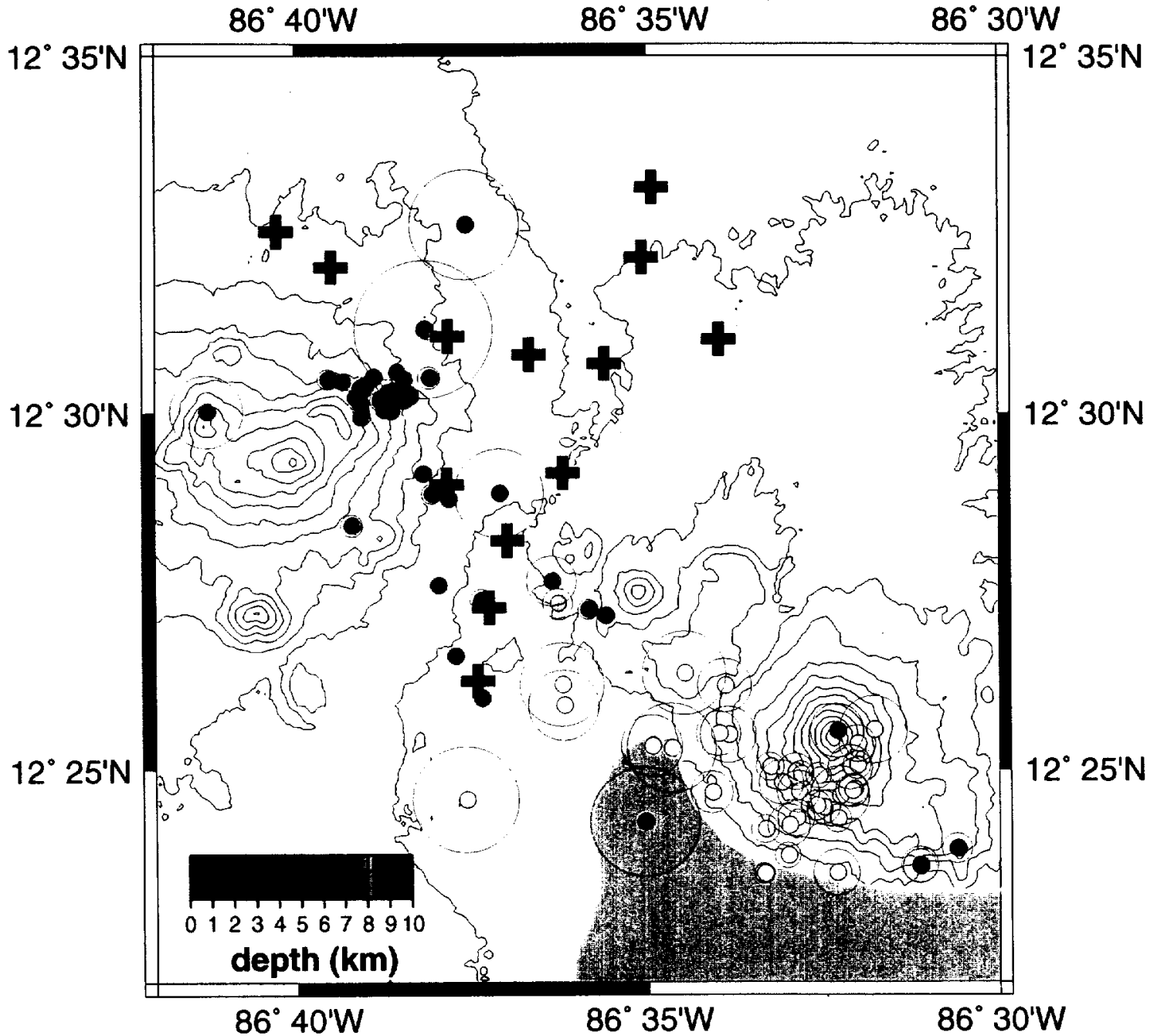

Figure 3. Seismic events located in the study area by our network: HYPO71 locations. The circles that are color coded by depth represent the locations based on a pre-determined velocity model for events during the period March 20 through April 9 in this area. The broader circles represent the formal location uncertainty from HYPO71. 


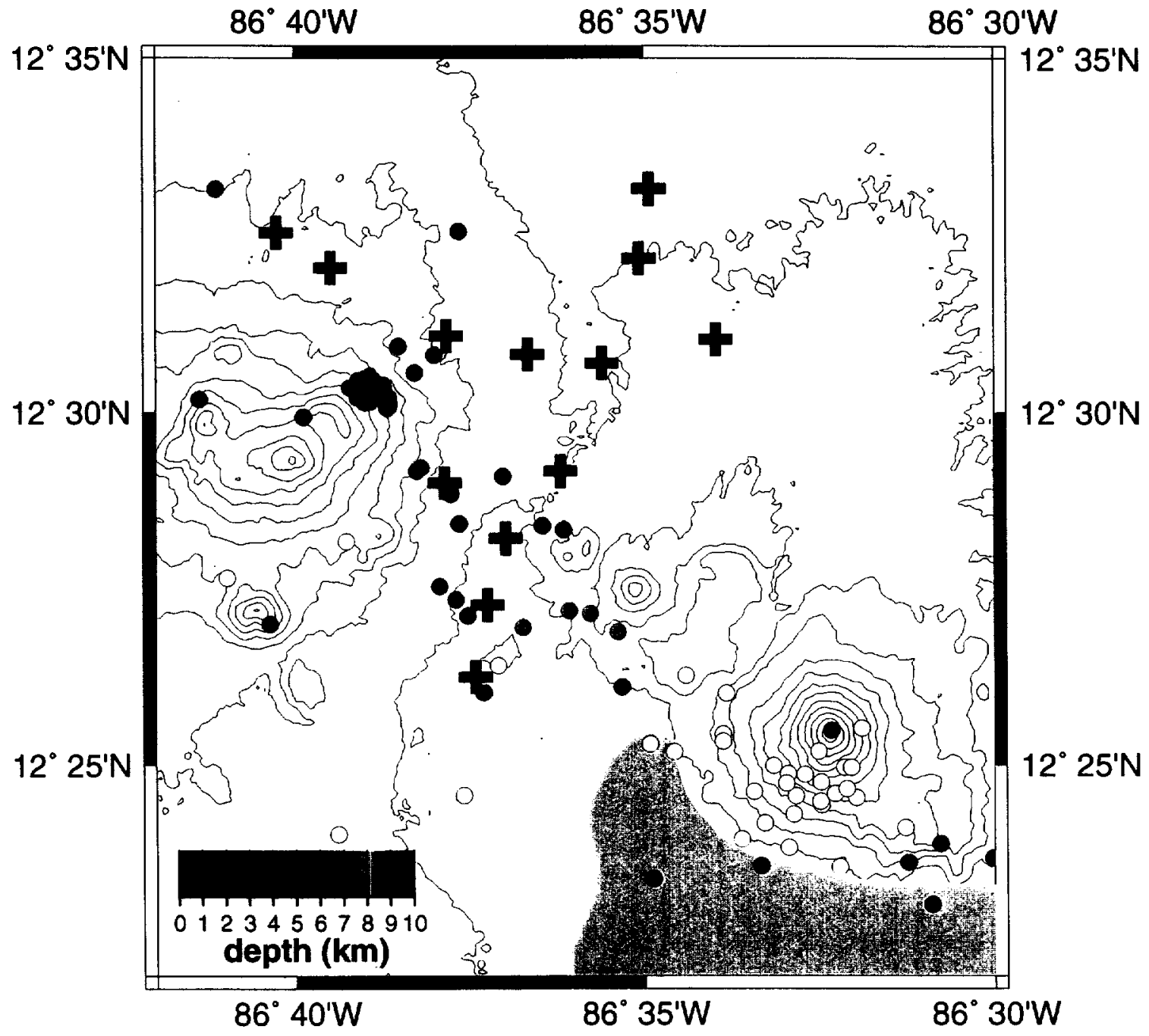

Figure 4. a) Seismic events located in the study area by our network: VELEST locations using all events. The circles that are color coded by depth represent the locations based on a joint inversion for hypocenters and $1-D$ velocity model for events during the period March 20 through April 9 in this area. The shallow cluster near El Hoyo appears much tighter in this inversion.

b) Velocity model derived from joint inversion of cluster events using final velocity from $4 \mathrm{a}$ ) as starting model.

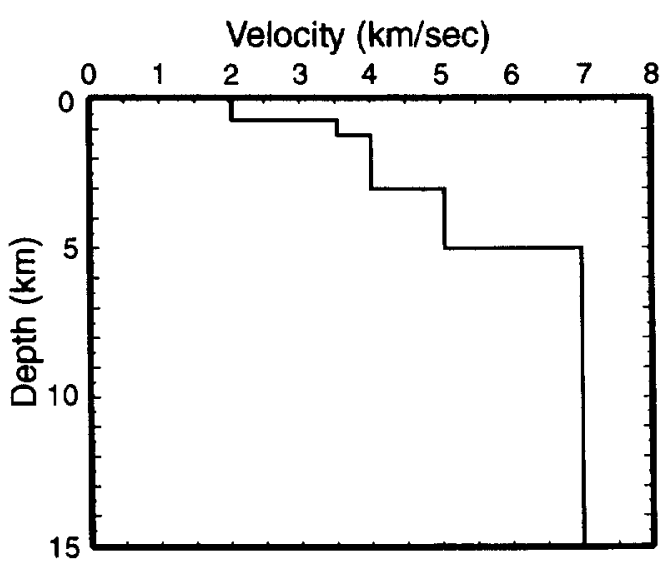



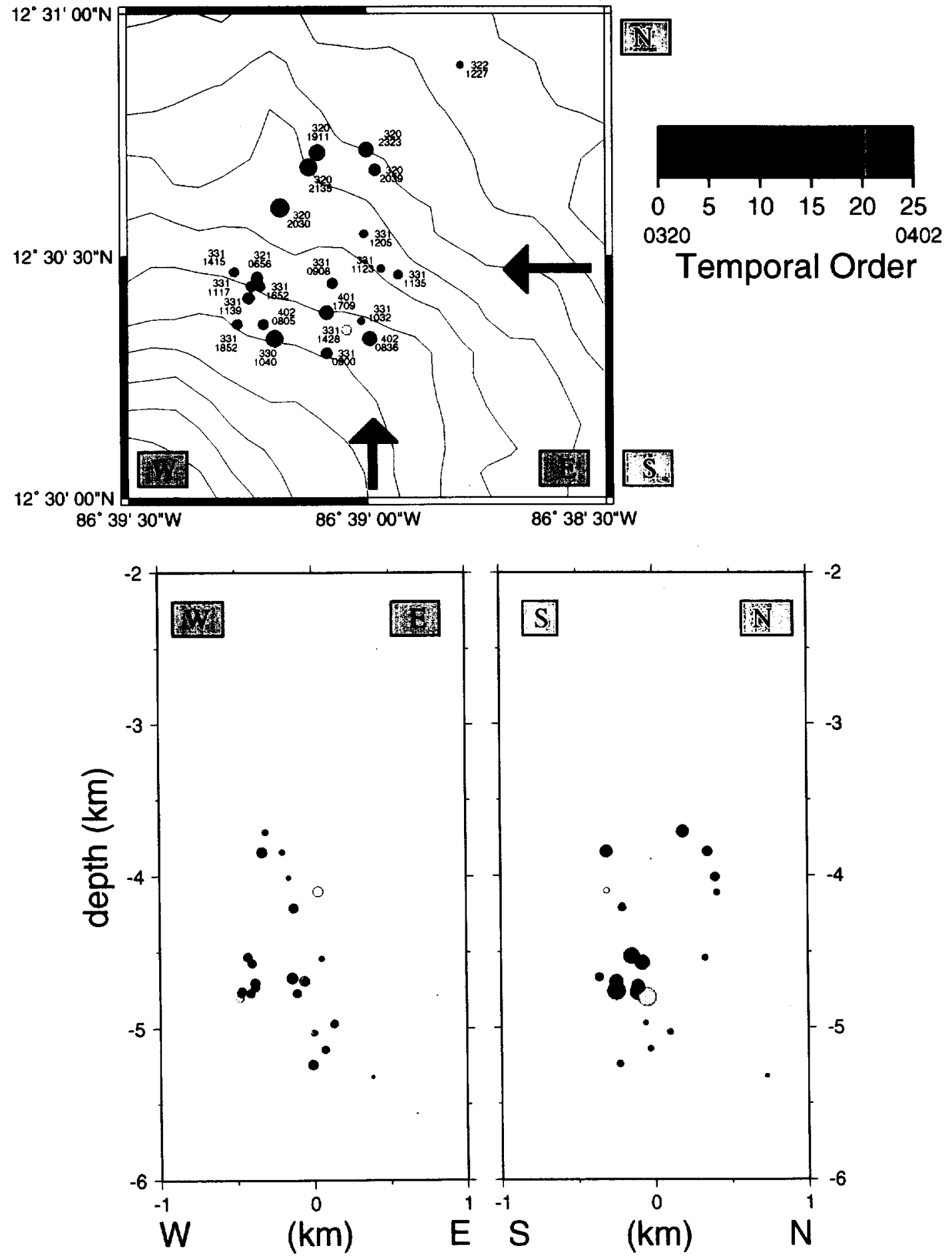

Figures 5,6, and 7. Relative locations of seismic events in the cluster. These figures show views of the cluster of events looking down (Fig.5 on top) or as denoted by arrows to the north and to the west for the depth sections. The extent of the lateral views are shown by the colored $\mathrm{S}-\mathrm{N}$ and $\mathrm{W}-\mathrm{E}$ in the figures. The color coding indicates the temporal order of occurrence of the events, while dates and times are denoted on the events in Fig. 5, top. The depth of the events, or their distance from view plane are scaled by size: deeper events or, for depth sections, events farther from the viewing plane are smaller. 


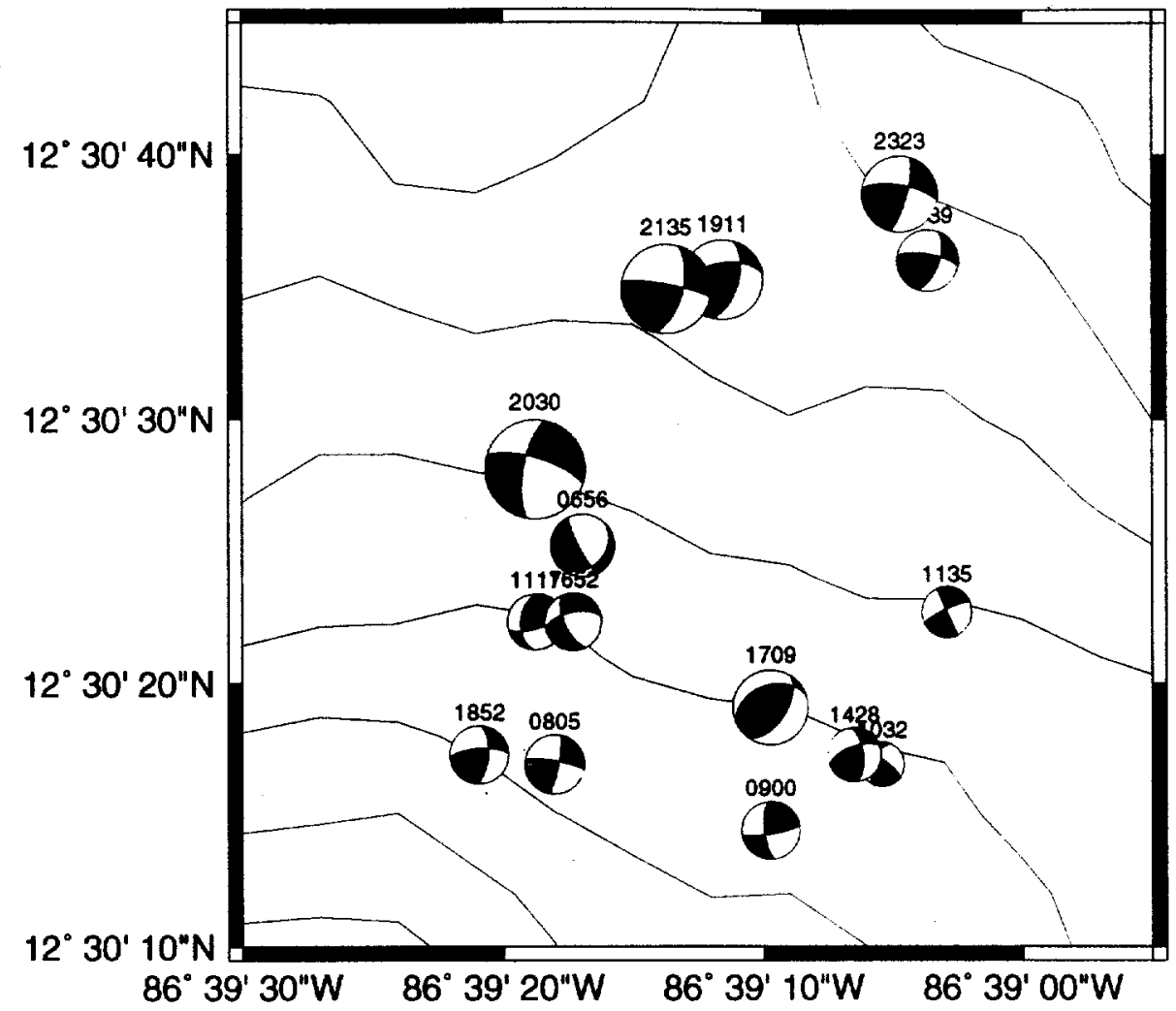

Figure 8. Lower hemisphere focal mechanisms for the cluster events. Dark areas are compression. Deeper events are shown with smaller symbols. 


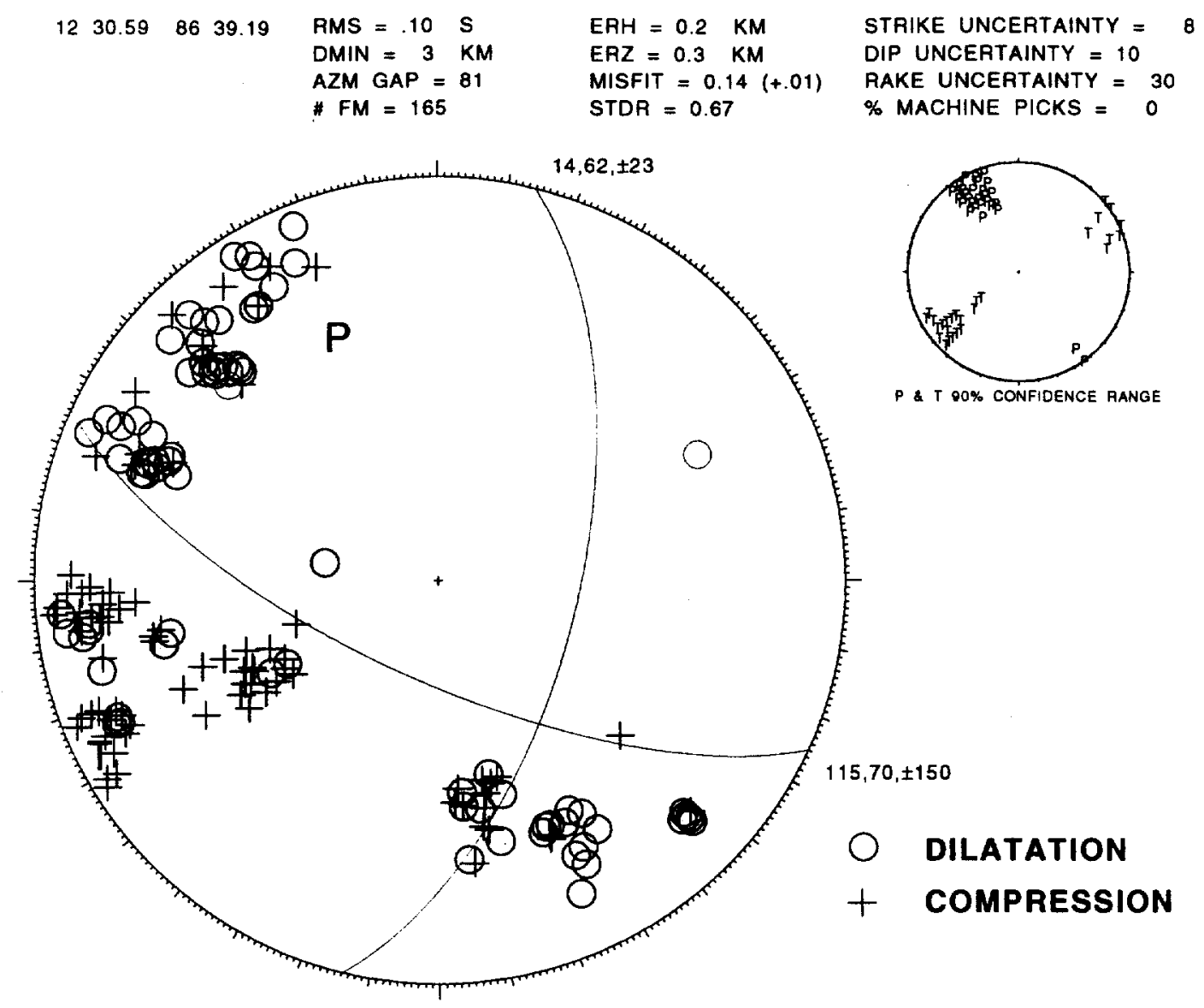

Figure 9. Composite focal mechanism for cluster events. This output file from VELEST shows that most of the events have consistent first motions, and indicate that the compression axis is aligned $\mathrm{N} 30^{\circ} \mathrm{W}$. 


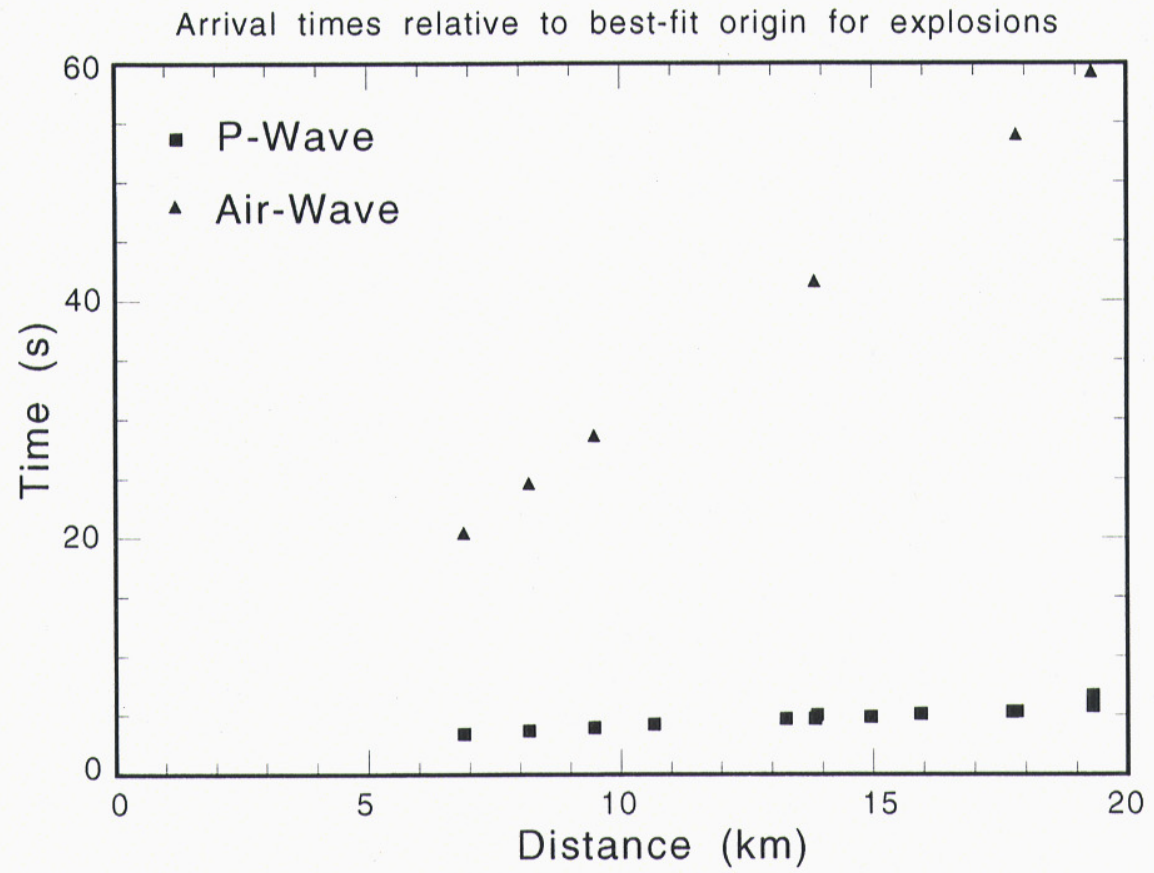

Figure 10. First arrival and air-wave arrival times from an explosion in Lake Nicaragua, plotted as a function of distance from the event. These data were used to estimate the location and time of the explosion, and those parameters were then used to calculate the zero-time and distance scaling for this plot.

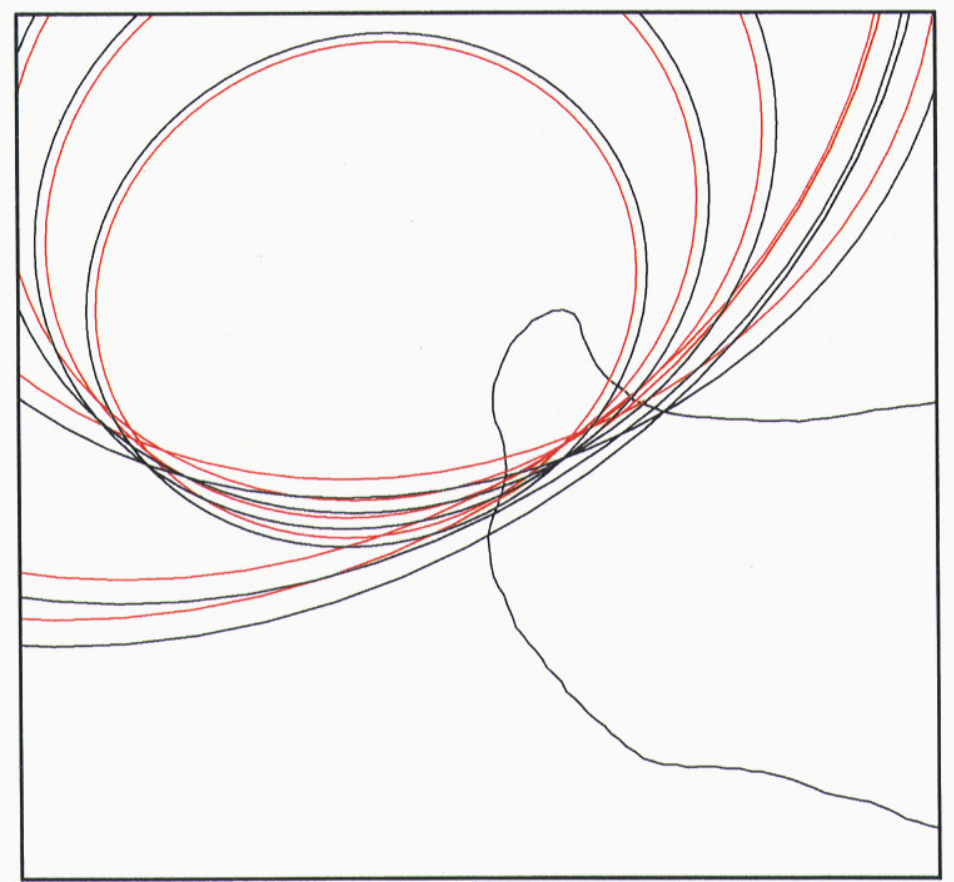

Figure 11. Estimation of explosion location from air-wave arrival times. Two sets of circles indicate the distance from stations assuming different sound speeds. Dashed $=$ speed in dry air at $0^{\circ} \mathrm{C}$ and the solid lines $=$ speed in dry air at $20^{\circ} \mathrm{C}$. 


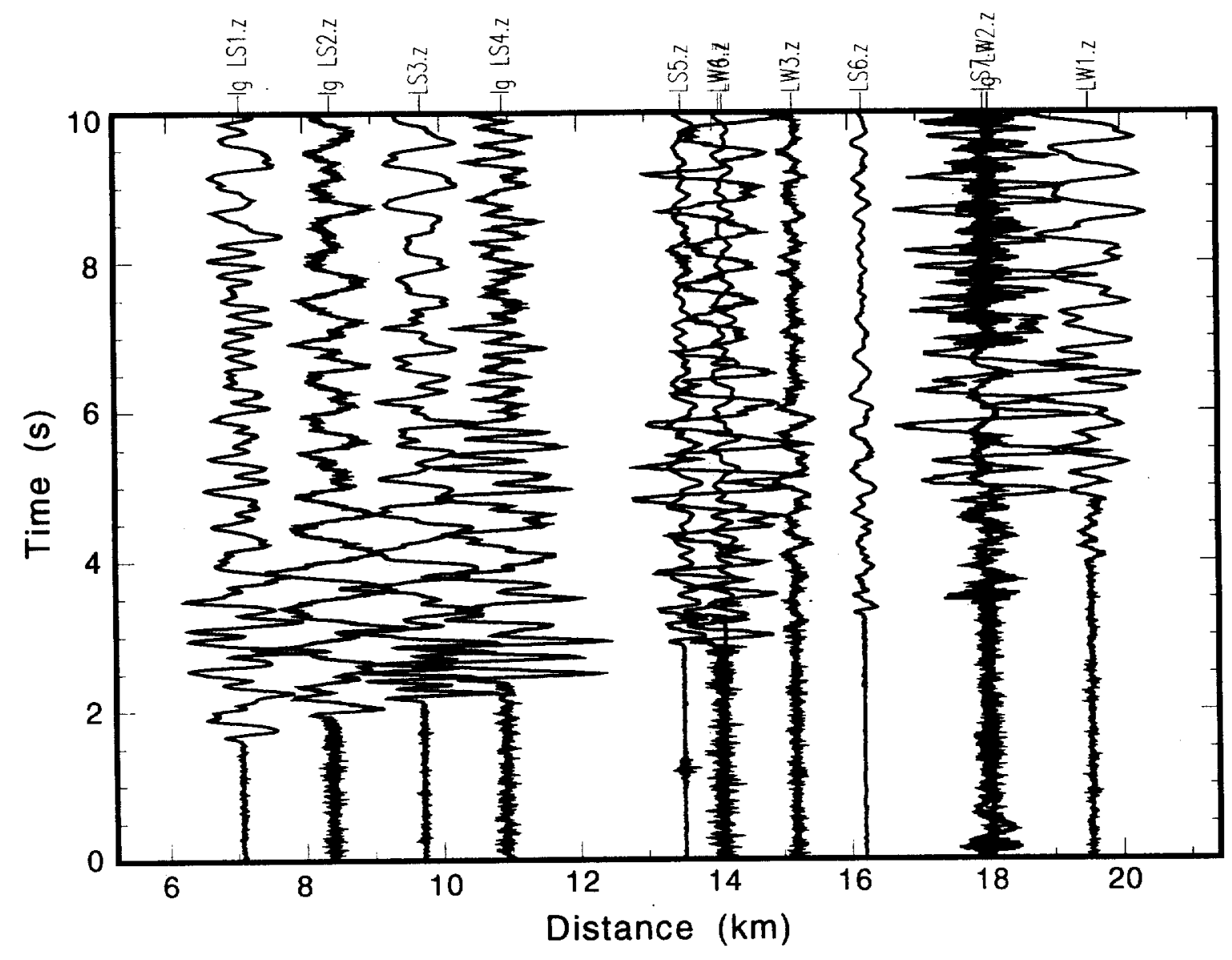

Figure 12. Arrivals from the explosions on vertical seismometers. All arrivals are plotted at the same scale and the signals were corrected approximately for geometrical spreading by multiplying by the distance to the source. 

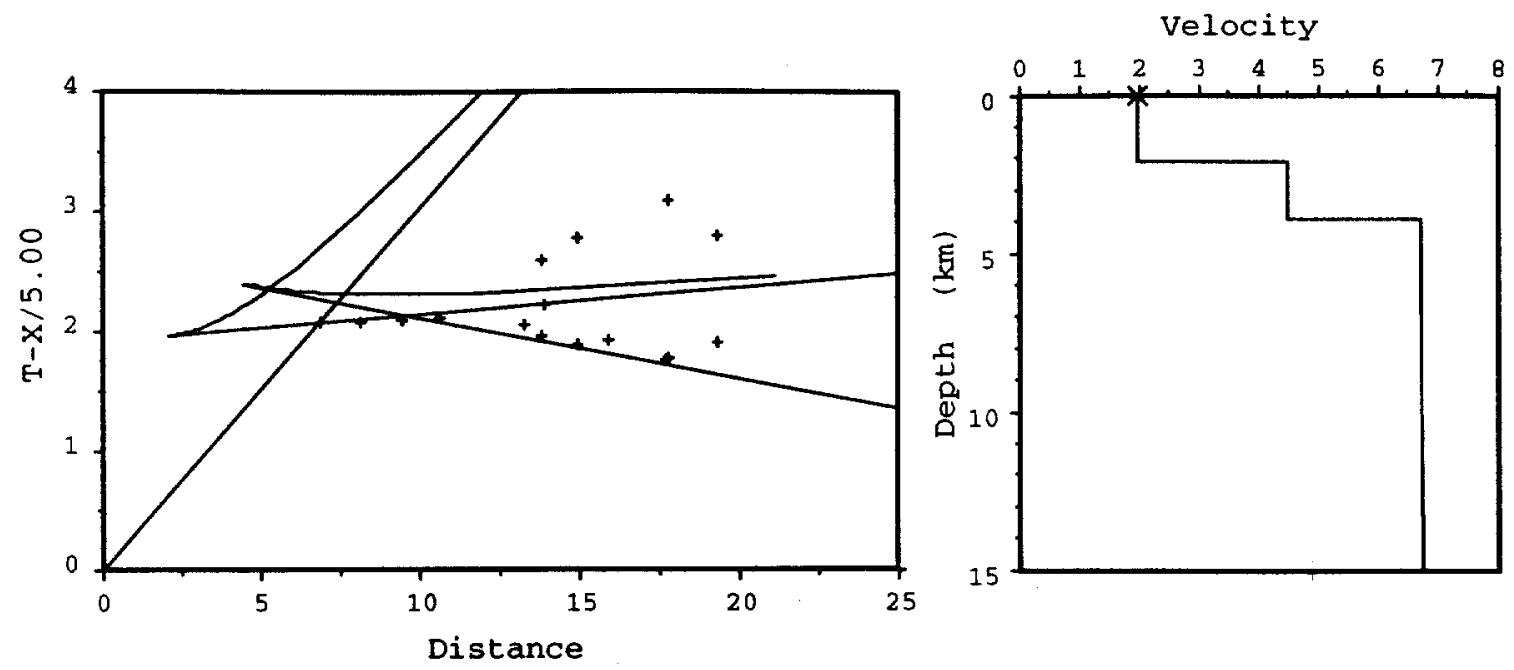

Figure 13. A simple P-velocity model to fit the data in Figure 12. The first and second arrival times, and the resulting travel-time curves are plotted in the upper figure as reduced travel-time, with a reducing velocity of $5 \mathrm{~km} / \mathrm{s}$. This model does not fit the later arrivals, and the refracted branch continues without dying out.
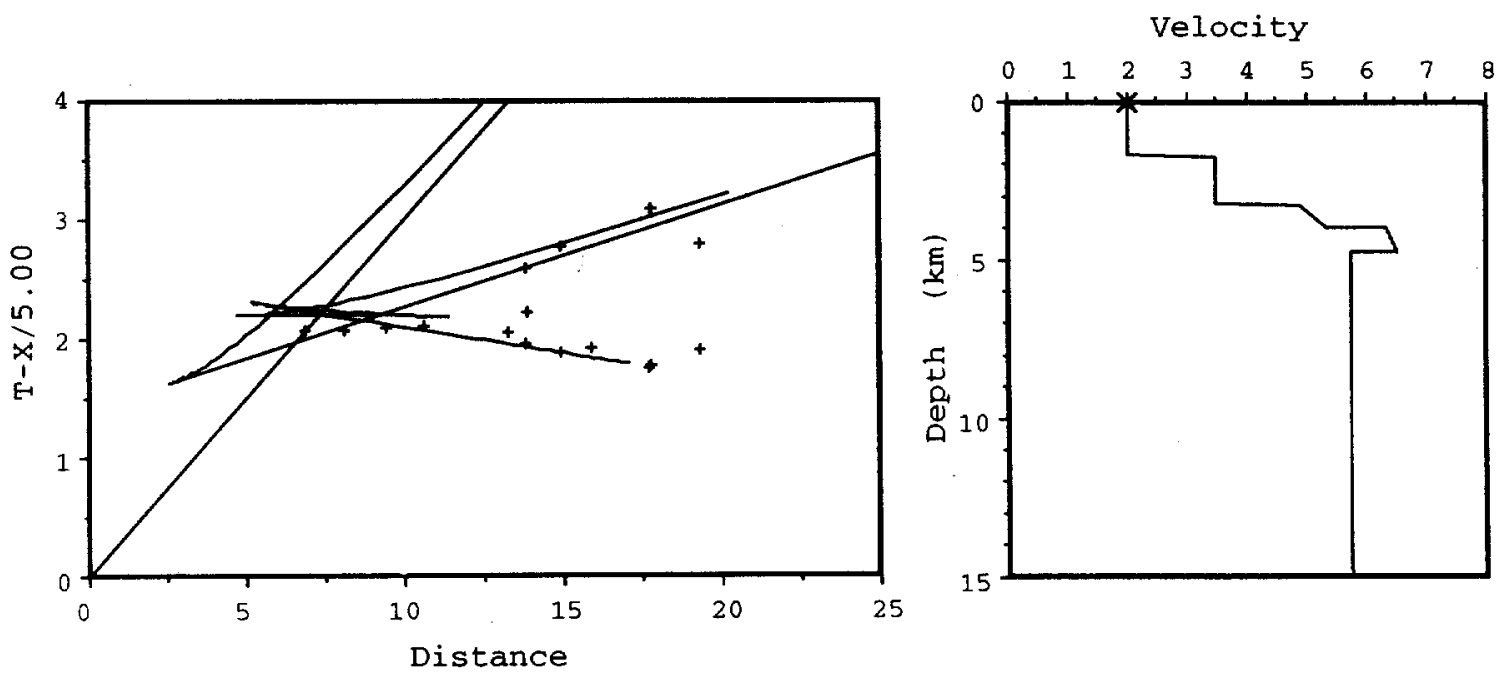

Figure 14. The preferred P-velocity model to fit the data in Figure 12. The first and second arrival times, and the resulting travel-time curves are plotted in the upper figure as reduced travel-time, with a reducing velocity of $5 \mathrm{~km} / \mathrm{s}$. 

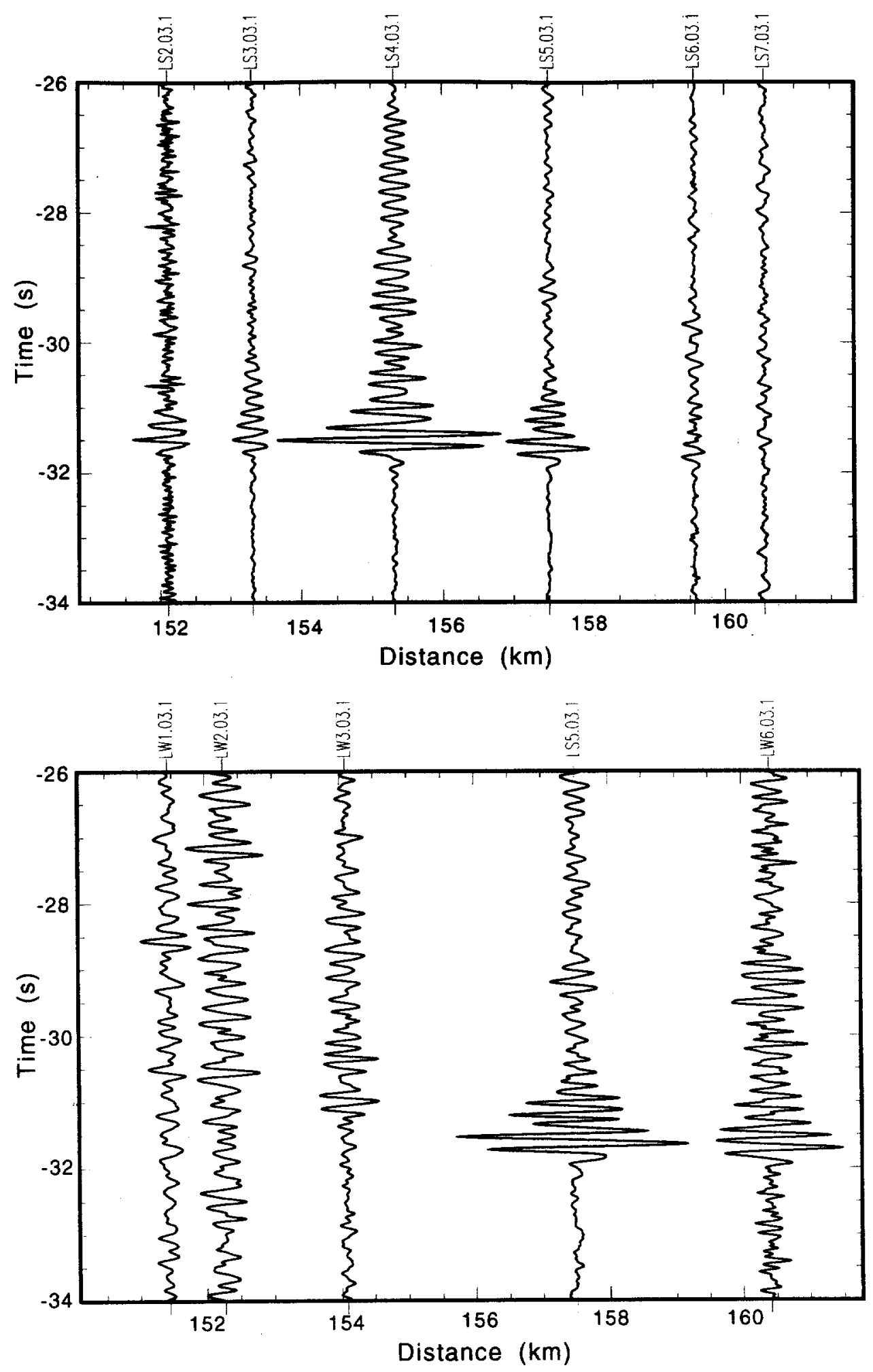

Figure 15 and 16. Observed airgun data, plotted as reduced travel time with a reduction velocity of $6 \mathrm{~km} / \mathrm{s}$. Figure 15 is the N-S profile, and Figure 16 is the E-W profile. All signals are shown at the same gain. These data have been corrected for distance as described in Figure 12. 


\section{References}

Burkart, B., and S. Self, (1985). Extension and rotation of crustal blocks in northern Central America and effect on the volcanic arc, Geology, 13, 22-26.

Elming, S- $\AA$, and T. Rasmussen, (1997). Results of magnetotelluric and gravimetric measurements in western Nicaragua, Central America, Geophys. J. Int., 128, 647-658.

Kissling, E., W.L. Ellsworth, D. Eberhardt-Phillips, and U. Kradolfer, (1994). Initial reference models in local earthquake tomography, J. Geophys. Res., 99, pp 19635-19646.

Leutgart, J.H. (1992). MacRay, Interactive Two-Dimensional Seismic Raytracing for the Macintosh ${ }^{\mathrm{TM}}$, US Geol. Surv. Open-File Rpt. 92-356.

Lee, W.H.K, and J.C. Lahr (1975). A computer program for determining hypocenter, magnitude, and first motion pattern of local earthquakes, US Geol. Surv. Open-file Rpt., 75-311.

McBirney, A.R. (1955). Thoughts on the eruptions of the Nicaraguan volcano Las Pilas, Bull. Volc., Series II, 17, 113-117.

McBirney, A.R., and H. Williams (1965). "Volcanic History of Nicaragua", University of California Publications in Geological Sciences, 55, Univ. of California Press, Berkeley and Los Angeles.

Weinberg, R.F., (1992). Neotectonic Development of Western Nicaragua, Tectonics, 11, 1010-1017.

Wessel, P. and W.H.F. Smith (1995). New version of the Generic Mapping Tools released, EOS Trans. Amer. Geophys. U., 76, 329. 


\section{Appendix I Summary of Event Locations}

The table are the locations of events in Figure 4 determined using VELEST. The $x, y, z$ positions are relative to a fixed geographical point.

\begin{tabular}{|c|c|c|c|c|c|c|c|c|c|c|c|c|}
\hline & & . & & & & & g & no & rms & $\mathrm{x}$ & & $\mathbf{z}$ \\
\hline 1 & $\begin{array}{l}\text { moda } \\
0320\end{array}$ & $\begin{array}{l}\text { hrmn } \\
0236\end{array}$ & $\begin{array}{c}\text { sec } \\
12.09\end{array}$ & & & & 00 & 5 & 0.026 & $\begin{array}{l}\mathrm{cm} \\
60\end{array}$ & -1 & 11.6 \\
\hline$\overline{2}$ & & 022 & 11.64 & & & & & 7 & & 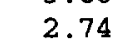 & & 6.1 \\
\hline 3 & & 1911 & & & & & 0.00 & 20 & & & & 3.46 \\
\hline 4 & & 1917 & 53.70 & $5 \mathrm{~N}$ & & & 0.00 & 5 & & & & 7.39 \\
\hline 5 & & 2030 & & 12.5 & & & 0.00 & 14 & & & -0.67 & 3.31 \\
\hline 6 & & 2039 & & 12. & & & 0.00 & 12 & & & & 3.49 \\
\hline 7 & & 2135 & & & & & 0.00 & 22 & & & & 3.46 \\
\hline 8 & & 02 & & $\mathbf{N}$ & & & 0.00 & 12 & & & & .99 \\
\hline 9 & & 23 & & $\mathbf{N}$ & & 3 & 00 & 17 & & & & 3.73 \\
\hline & & 6 & & & & 0.37 & 00 & 13 & & & & 0.37 \\
\hline & & 0149 & 41. & 12. & & 6.14 & 0.00 & 12 & & & & 6.14 \\
\hline 2 & & 0656 & 5.92 & 12. & & 3.61 & 2.29 & 15 & & & & 3.61 \\
\hline & & 1227 & 37.49 & 12 . & & 3.53 & 0.00 & 7 & & & & 3.53 \\
\hline & & 1454 & 44.79 & 12. & & 16.02 & 2.26 & 11 & & & -13.49 & 16.02 \\
\hline & 5 & 0831 & 52.42 & 12.5 & & 0.27 & 3.50 & 17 & & & & 0.27 \\
\hline 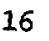 & 6 & 0851 & & 12.4 & & & 0.00 & 16 & & & & 8.92 \\
\hline & 6 & 1035 & & 12.5 & & 8 & 3.53 & 12 & & & & .00 \\
\hline & & 0226 & 58.27 & 12.4 & & 4.73 & 59 & 6 & & & -3.98 & 4.73 \\
\hline & & 0720 & 58. & 12. & & 13.64 & 0.00 & 9 & & 2 & -12 & .64 \\
\hline & & 0801 & 16 & 12. & & 11.61 & 2.72 & 12 & & & & 1.61 \\
\hline & & 0826 & 20 & 12. & & 8.19 & 0.00 & 12 & & & -8 & 8.1 \\
\hline 2 & & 0826 & & & & 3.20 & 0 . & 9 & & & -2 & .2 \\
\hline & & 0827 & & 12 & & 3.57 & 0 . & 9 & & & -3 & $3.5^{\prime}$ \\
\hline 4 & & 1435 & & 12 & & 7.42 & & 14 & & & -4 & 7.42 \\
\hline 25 & & 1840 & & 12. & & 2 & & 18 & & & -15.98 & 4.72 \\
\hline & & 1843 & 53 & 12. & & 15.86 & & 15 & & & 7 & 5.86 \\
\hline & 96 & 0513 & & 12. & & 2.26 & & 15 & & & 8 & .26 \\
\hline 28 & 96 & 0716 & 49.47 & 12. & & 8.81 & & 7 & & & -0 & .81 \\
\hline 29 & & & 0 & 12.4 & & 11.60 & & 10 & & & -4 & 1.60 \\
\hline 30 & 96 & .1316 & 9.37 & 12.3 & & 12.76 & & 17 & & & -16 & 2.76 \\
\hline & & 1345 & & 12.3 & & 0.81 & 2 . & 16 & & 1 & -1 & 0.81 \\
\hline & & 1351 & & 12. & & .10 & 0. & 13 & & & -1 & .10 \\
\hline & & 1401 & & 12. & & 12.36 & 2. & 10 & & & & 12.36 \\
\hline 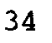 & & 1 & & 70 & & 19 & & 16 & & & -2 & 0.09 \\
\hline & & 0 & & T & & 5 & & 8 & & & -1 & .6 \\
\hline & & 3 & & 1 & & 3 & & 17 & & & 1 & .8 \\
\hline 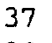 & & 97 & & 12 & & 9 & & 5 & & & & 6 \\
\hline 0 & & & & & & & & 10 & & & & 10 \\
\hline 39 & & & & & & & & 11 & & & & .29 \\
\hline 40 & & & & & & 5.29 & & 6 & & & -3.72 & .29 \\
\hline 41 & 960 & 0142 & 49.53 & 12.3 & & 12.65 & & 13 & & 8.22 & -14.25 & 12.65 \\
\hline 42 & & 0900 & 49.18 & 12.5 & & 3.52 & & 13 & & & -0.60 & 3.52 \\
\hline 43 & & 0908 & 2.03 & 12.5 & & 3.77 & & 10 & & & -0.58 & 3.77 \\
\hline 45 & & 53 & 46 & 12. & & -0.01 & & 12 & & & -3.22 & -0.01 \\
\hline 46 & & 2 & & 12. & & 6.38 & & 13 & & & & .3 \\
\hline 47 & & & & 12. & & & & 17 & & & -1 & 0 \\
\hline 48 & & & & & & & & 8 & & & & 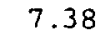 \\
\hline 49 & & 1135 & & 12.5 & & 4.58 & & 12 & & & & 1.5 \\
\hline 50 & & 1139 & & & & & & 8 & & & & 3.0 \\
\hline 51 & & 1205 & 36.14 & 12.5 & & 3.74 & & 7 & & & & 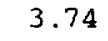 \\
\hline 52 & 1 & 1415 & 42.00 & 12.5 & & 3.52 & & 11 & & & -0.61 & 3.52 \\
\hline 53 & 1 & 1428 & 52 & 12.4 & & 3.19 & 0.00 & 16 & & & -1.38 & 3.19 \\
\hline & 1 & 1642 & 58.84 & 12.4 & & 9.34 & 0.00 & 15 & & -0 & -8.18 & 9.3 \\
\hline & 1 & 1652 & 20.22 & 12.4 & ow & 3.10 & 0. & 16 & & & -1.57 & 3.1 \\
\hline & & 1852 & & 12.5 & & 5.33 & 0.00 & 19 & & & -0.92 & 5.33 \\
\hline & & 1944 & & 12.4 & & & 0.00 & 18 & & & & 7.4 \\
\hline & & & & 12.3 & $66 \mathrm{~W}$ & 1.78 & 2.81 & 13 & & -7.91 & -15.72 & 11.7 \\
\hline
\end{tabular}


Appendix I

Summary of Event Locations

$\begin{array}{rrrrr}59 & 960401 & 1111 & 33.54 & 12.3913 \mathrm{~N} \\ 60 & 960401 & 1709 & 4.28 & 12.5025 \mathrm{~N} \\ 61 & 960402 & 0805 & 40.26 & 12.5001 \mathrm{~N} \\ 62 & 960402 & 0836 & 52.33 & 12.4992 \mathrm{~N} \\ 63 & 960403 & 0046 & 33.46 & 12.4341 \mathrm{~N} \\ 64 & 960405 & 0507 & 45.51 & 12.4538 \mathrm{~N} \\ 65 & 960405 & 0540 & 15.28 & 12.5765 \mathrm{~N} \\ 66 & 960405 & 0851 & 54.99 & 12.3701 \mathrm{~N} \\ 67 & 960405 & 1104 & 46.31 & 12.4012 \mathrm{~N} \\ 68 & 960405 & 1111 & 38.12 & 12.3841 \mathrm{~N} \\ 69 & 960405 & 1153 & 6.74 & 12.3322 \mathrm{~N} \\ 70 & 960405 & 2239 & 48.69 & 12.3842 \mathrm{~N} \\ 71 & 960406 & 0029 & 16.06 & 12.3607 \mathrm{~N} \\ 72 & 960406 & 0345 & 55.07 & 12.3747 \mathrm{~N} \\ 73 & 960406 & 0507 & 30.63 & 12.3781 \mathrm{~N} \\ 74 & 960406 & 0637 & 33.41 & 12.3848 \mathrm{~N} \\ 75 & 960406 & 0644 & 28.79 & 12.4218 \mathrm{~N} \\ 76 & 960406 & 0656 & 45.65 & 12.4072 \mathrm{~N} \\ 77 & 960406 & 0659 & 29.34 & 12.3838 \mathrm{~N} \\ 78 & 960406 & 0735 & 28.96 & 12.3686 \mathrm{~N} \\ 79 & 960406 & 0754 & 23.99 & 12.3475 \mathrm{~N} \\ 80 & 960406 & 0835 & 22.00 & 12.3816 \mathrm{~N} \\ 81 & 960406 & 1104 & 12.06 & 12.3822 \mathrm{~N} \\ 82 & 960406 & 1308 & 5.14 & 12.3683 \mathrm{~N} \\ 83 & 960406 & 1336 & 12.70 & 12.3565 \mathrm{~N} \\ 84 & 960406 & 1359 & 2.94 & 12.3759 \mathrm{~N} \\ 85 & 960406 & 1437 & 7.80 & 12.3781 \mathrm{~N} \\ 86 & 960406 & 1458 & 33.87 & 12.3854 \mathrm{~N} \\ 87 & 960406 & 2116 & 31.73 & 12.3472 \mathrm{~N} \\ 88 & 960406 & 2136 & 19.47 & 12.4578 \mathrm{~N} \\ 89 & 960406 & 2302 & 52.70 & 12.4181 \mathrm{~N} \\ 90 & 960406 & 2342 & 9.59 & 12.3919 \mathrm{~N} \\ 91 & 960407 & 0128 & 36.25 & 12.3721 \mathrm{~N} \\ 92 & 960407 & 1513 & 40.11 & 12.4070 \mathrm{~N} \\ 93 & 960408 & 0404 & 21.10 & 12.4483 \mathrm{~N} \\ 94 & 960408 & 0730 & 47.34 & 12.4376 \mathrm{~N} \\ 95 & 960408 & 0749 & 40.94 & 12.4613 \mathrm{~N} \\ 96 & 960408 & 1040 & 17.35 & 12.4651 \mathrm{~N} \\ 97 & 960409 & 0449 & 40.60 & 12.4195 \mathrm{~N} \\ 98 & 960328 & 1721 & 14.30 & 12.3895 \mathrm{~N}\end{array}$
$86.5300 \mathrm{~W}$ $86.6576 \mathrm{~W}$ $86.6572 \mathrm{~W}$ $86.6483 \mathrm{~W}$ $86.5939 \mathrm{~W}$ $86.6058 \mathrm{~W}$ $86.7732 \mathrm{~W}$ $86.4956 \mathrm{~W}$ $86.5289 \mathrm{~W}$ $86.5028 \mathrm{~W}$ $86.4602 \mathrm{~W}$ $86.5334 \mathrm{~W}$ $86.4908 \mathrm{~W}$ $86.5146 \mathrm{~W}$ $86.5164 W$ $86.5304 W$ $86.5371 \mathrm{~W}$ $86.5329 W$ $86.5182 W$ $86.5182 W$ $86.5117 W$ $86.5755 \mathrm{~W}$ $86.5030 \mathrm{~W}$ $86.4987 \mathrm{~W}$ $86.4898 \mathrm{~W}$ $86.5168 \mathrm{~W}$ $86.5053 \mathrm{~W}$ $86.5535 \mathrm{~W}$ $86.4884 \mathrm{~W}$ $86.7968 \mathrm{~W}$ $86.5606 \mathrm{~W}$ $86.4971 \mathrm{~W}$ $86.5089 \mathrm{~W}$ $86.6214 \mathrm{~W}$ $86.6414 \mathrm{~W}$ $86.5898 \mathrm{~W}$ $86.7152 \mathrm{~W}$ $86.6757 \mathrm{~W}$ $86.6894 \mathrm{~W}$ $86.5812 \mathrm{~W}$
15.282 .93 3.510 .00 3.240 .00 $3.18 \quad 2.24$ 9.630 .00 4.830 .00 $11.42 \quad 0.00$ $11.82 \quad 0.00$ $17.60 \quad 0.00$ 15.670 .00 15.810 .00 17.790 .00 $0.66 \quad 0.00$ 12.810 .00 $11.97 \quad 0.00$ $14.06 \quad 0.00$ 8.660 .00 14.410 .00 13.650 .00 14.350 .00 13.860 .00 18.120 .00 13.490 .00 14.990 .00 $0.90 \quad 0.00$ $15.94 \quad 0.00$ 12.880 .00 18.340 .00 10.320 .00 $2.32 \quad 0.00$ $16.15 \quad 0.00$ 13.560 .00 13.160 .00 8.960 .00 $8.74 \quad 0.00$ $9.64 \quad 0.00$ 12.710 .00 $16.56 \quad 0.00$ $\begin{array}{lll}7.27 & 0.00\end{array}$ 0.010 .00
$15 \quad 0.076$ $\begin{array}{ll}11 & 0.050\end{array}$ $\begin{array}{ll}16 & 0.068\end{array}$ $\begin{array}{ll}12 & 0.029\end{array}$ $\begin{array}{ll}15 & 0.060\end{array}$ $\begin{array}{ll}12 & 0.277\end{array}$ 220.076

90.039 140.096 $\begin{array}{ll}13 & 0.121\end{array}$ $\begin{array}{ll}12 & 0.382\end{array}$ $\begin{array}{ll}15 & 0.072\end{array}$ $\begin{array}{lll}19 & 0.072\end{array}$ 110.035 $\begin{array}{ll}13 & 0.072\end{array}$ 120.053 $\begin{array}{ll}6 & 0.038\end{array}$ $\begin{array}{ll}11 & 0.052\end{array}$ $\begin{array}{ll}18 & 0.051\end{array}$ 150.063 $10 \quad 0.053$ $\begin{array}{ll}7 & 0.033\end{array}$ 120.114 140.069 $20 \quad 0.052$ $14 \quad 0.102$ $\begin{array}{ll}14 & 0.047\end{array}$ $\begin{array}{lll}12 & 0.117\end{array}$ $14 \quad 0.082$ $\begin{array}{ll}7 & 0.052\end{array}$ $\begin{array}{lll}10 & 0.113\end{array}$ $\begin{array}{lll}16 & 0.122\end{array}$ $\begin{array}{lll}18 & 0.085\end{array}$ 100.039 100.059

$13 \quad 0.060$

$\begin{array}{ll}6 & 0.182\end{array}$

$\begin{array}{lll}10 & 0.124\end{array}$ $\begin{array}{ll}6 & 0.196\end{array}$ $16 \quad 0.882$

$\begin{array}{rrr}-6.88 & -13.32 & 15.28 \\ 6.99 & -1.02 & 3.51 \\ 6.94 & -1.28 & 3.24 \\ 5.98 & -1.39 & 3.18 \\ 0.06 & -8.58 & 9.63 \\ 1.35 & -6.41 & 4.83 \\ 19.55 & 7.17 & 11.42 \\ -10.62 & -15.67 & 11.82 \\ -7.00 & -12.22 & 17.60 \\ -9.84 & -14.12 & 15.67 \\ -14.47 & -19.86 & 15.81 \\ -6.51 & -14.11 & 17.79 \\ -11.15 & -16.71 & 0.66 \\ -8.56 & -15.15 & 12.81 \\ -8.36 & -14.77 & 11.97 \\ -6.84 & -14.04 & 14.06 \\ -6.11 & -9.94 & 8.66 \\ -6.57 & -11.56 & 14.41 \\ -8.17 & -14.15 & 13.65 \\ -8.16 & -15.83 & 14.35 \\ -8.87 & -18.16 & 13.86 \\ -1.94 & -14.39 & 18.12 \\ -9.82 & -14.32 & 13.49 \\ -10.29 & -15.86 & 14.99 \\ -11.26 & -17.16 & 0.90 \\ -8.31 & -15.02 & 15.94 \\ -9.56 & -14.77 & 12.88 \\ -4.33 & -13.97 & 18.34 \\ -11.41 & -18.19 & 10.32 \\ 22.12 & -5.97 & 2.32 \\ -3.56 & -10.35 & 16.15 \\ -10.46 & -13.25 & 13.56 \\ -9.17 & -15.44 & 13.16 \\ 3.06 & -11.59 & 8.96 \\ 5.23 & -7.01 & 8.74 \\ -0.38 & -8.20 & 9.64 \\ 13.25 & -5.58 & 12.71 \\ 8.95 & -5.15 & 16.56 \\ 10.45 & -10.20 & 7.27 \\ -1.32 & -13.52 & 0.01\end{array}$


Appendix I

Summary of Event Locations

These are locations for the cluster of events plotted in Figures 5, 6, and 7. The locations are derived from VELEST as a joint solution with the velocity model.

\begin{tabular}{rcrrrrr} 
& date & \multicolumn{2}{c}{ origin } & latitude & longitude \\
1 & 960320 & 1911 & 6.51 & $12.5119 \mathrm{~N}$ & $86.6517 \mathrm{~W}$ \\
2 & 960320 & 2030 & 26.14 & $12.5100 \mathrm{~N}$ & $86.6530 \mathrm{~W}$ \\
3 & 960320 & 2039 & 16.59 & $12.5113 \mathrm{~N}$ & $86.6497 \mathrm{~W}$ \\
4 & 960320 & 2135 & 59.39 & $12.5114 \mathrm{~N}$ & $86.6520 \mathrm{~W}$ \\
5 & 960320 & 2302 & 31.91 & $12.5004 \mathrm{~N}$ & $86.6413 \mathrm{~W}$ \\
6 & 960320 & 2323 & 53.47 & $12.5120 \mathrm{~N}$ & $86.650 \mathrm{~W}$ \\
7 & 960321 & 0149 & 41.63 & $12.5217 \mathrm{~N}$ & $86.6440 \mathrm{~W}$ \\
8 & 960321 & 0656 & 6.34 & $12.5076 \mathrm{~N}$ & $86.6538 \mathrm{~W}$ \\
9 & 960322 & 1227 & 37.77 & $12.5149 \mathrm{~N}$ & $86.6467 \mathrm{~W}$ \\
10 & 960326 & 1035 & 5.89 & $12.5108 \mathrm{~N}$ & $86.7531 \mathrm{~W}$ \\
11 & 960330 & 1040 & 4.98 & $12.5055 \mathrm{~N}$ & $86.6532 \mathrm{~W}$ \\
12 & 960331 & 0900 & 49.50 & $12.5050 \mathrm{~N}$ & $86.6514 \mathrm{~W}$ \\
13 & 960331 & 0908 & 2.45 & $12.5074 \mathrm{~N}$ & $86.6512 \mathrm{~W}$ \\
14 & 960331 & 1032 & 15.00 & $12.5061 \mathrm{~N}$ & $86.6502 \mathrm{~W}$ \\
15 & 960331 & 1117 & 47.89 & $12.5073 \mathrm{~N}$ & $86.6540 \mathrm{~W}$ \\
16 & 960331 & 1123 & 36.75 & $12.5079 \mathrm{~N}$ & $86.6495 \mathrm{~W}$ \\
17 & 960331 & 1135 & 4.67 & $12.5077 \mathrm{~N}$ & $86.6489 \mathrm{~W}$ \\
18 & 960331 & 1139 & 15.76 & $12.5069 \mathrm{~N}$ & $86.6541 \mathrm{~W}$ \\
19 & 960331 & 1205 & 36.59 & $12.5091 \mathrm{~N}$ & $86.6501 \mathrm{~W}$ \\
20 & 960331 & 1415 & 42.37 & $12.5078 \mathrm{~N}$ & $86.6546 \mathrm{~W}$ \\
21 & 960331 & 1428 & 2.86 & $12.5058 \mathrm{~N}$ & $86.6507 \mathrm{~W}$ \\
22 & 960331 & 1652 & 20.61 & $12.5073 \mathrm{~N}$ & $86.6537 \mathrm{~W}$ \\
23 & 960331 & 1852 & 10.25 & $12.5060 \mathrm{~N}$ & $86.6545 \mathrm{~W}$ \\
24 & 960401 & 1709 & 4.74 & $12.5064 \mathrm{~N}$ & $86.6514 \mathrm{~W}$ \\
25 & 960402 & 0805 & 40.69 & $12.5060 \mathrm{~N}$ & $86.6536 \mathrm{~W}$ \\
26 & 960402 & 0836 & 52.70 & $12.5055 \mathrm{~N}$ & $86.6499 \mathrm{~W}$
\end{tabular}

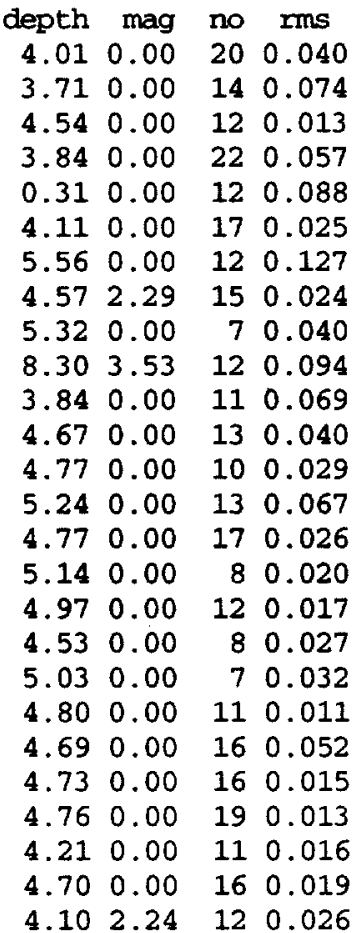




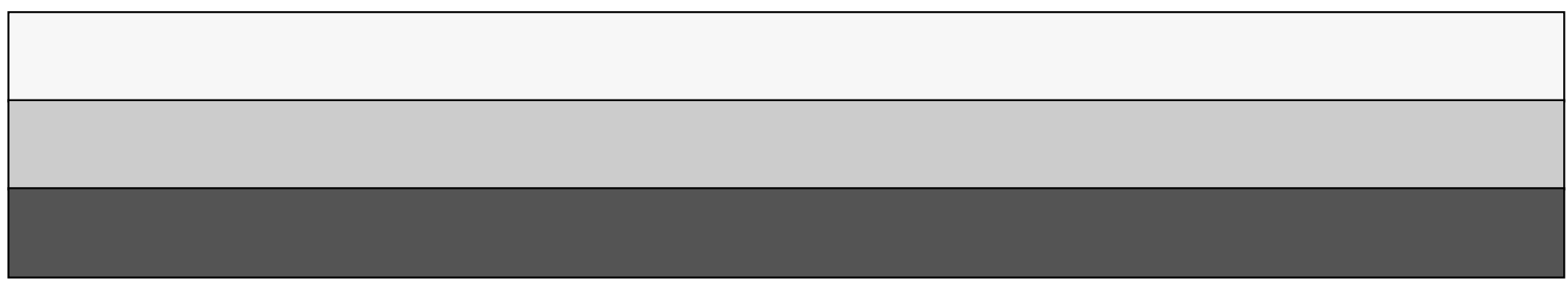

